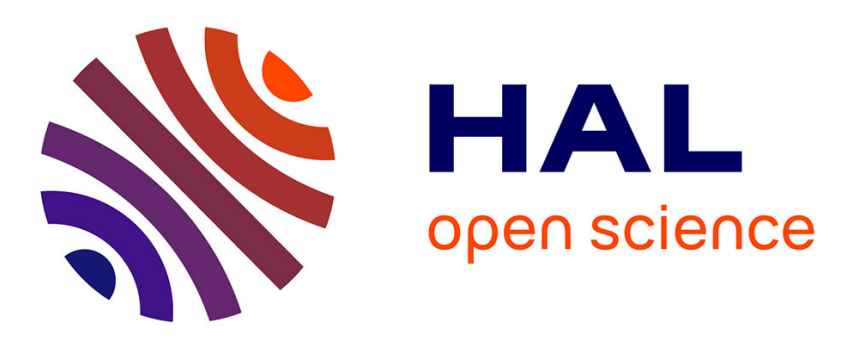

\title{
A deterministic approach for predicting the transformation of starch suspensions in tubular heat exchangers
}

Artemio Plana-Fattori, Denis Flick, Fabrice Ducept, Christophe Doursat, Camille Michon, Samir Mezdour

\section{To cite this version:}

Artemio Plana-Fattori, Denis Flick, Fabrice Ducept, Christophe Doursat, Camille Michon, et al.. A deterministic approach for predicting the transformation of starch suspensions in tubular heat exchangers. Journal of Food Engineering, 2016, 171, pp.28-36. 10.1016/j.jfoodeng.2015.10.002 . hal01232650

\section{HAL Id: hal-01232650 \\ https://hal.science/hal-01232650}

Submitted on 1 Feb 2021

HAL is a multi-disciplinary open access archive for the deposit and dissemination of scientific research documents, whether they are published or not. The documents may come from teaching and research institutions in France or abroad, or from public or private research centers.
L'archive ouverte pluridisciplinaire HAL, est destinée au dépôt et à la diffusion de documents scientifiques de niveau recherche, publiés ou non, émanant des établissements d'enseignement et de recherche français ou étrangers, des laboratoires publics ou privés. 
1 A deterministic approach for predicting the transformation of starch suspensions in

2 tubular heat exchangers

3

4 A. Plana-Fattori ${ }^{1,2, \#,}$

$5 \quad$ D. Flick ${ }^{1,2}$,

6 F. Ducept ${ }^{1,2}$,

7 C. Doursat ${ }^{1,2}$,

8 C. Michon ${ }^{1,2}$,

9 S. Mezdour ${ }^{1,2}$

10

11 1) AgroParisTech, UMR1145 Ingénierie Procédés Aliments, F-75231 Paris, France

2) INRA, UMR1145 Ingénierie Procédés Aliments, F-91300 Massy, France

13

14 \# Corresponding author address:

15 Artemio Plana-Fattori, AgroParisTech, 16 rue Claude Bernard, 75231 Paris, France;

16 e-mail: artemio.planafattori@agroparistech.fr 


\section{Abstract}

20 Numerical modeling of fluid flow, heat transfer and transformation is conducted for an

21 aqueous suspension of starch granules running throughout a four-heating-section tubular 22 exchanger. The numerical model considers the transformation kinetics and the rheological 23 behavior of the starch suspension as determined from laboratory work; further, the model 24 includes the geometrical characteristics of the heat exchanger, as well as the operating 25 conditions which were considered in running it. Model predictions are compared with results 26 from experimental work, after sampling the starch suspension under thermal processing and 27 later characterizing it using laboratory techniques. The numerical model predicts the bulk 28 swelling state of the starch suspension at a level of agreement $(-41 \%$ in volume mean 29 diameter increase) which is better than the one reached after assuming plug-flow and radially30 independent temperature $(-66 \%)$. The inclusion of two-way coupling between the relevant 31 phenomena constitutes therefore a positive improvement. 


\section{Introduction}

Manufacturing food products in a reproducible manner requires understanding the mechanisms which drive the transformation of the ingredients along the processing pathway. For instance, in dairy desserts the milk is mixed with starch, to which carrageenan is added as a gelling agent (Doublier and Durand, 2008). Experimental work at laboratory scale has been conducted in order to study the influence of thermal treatment on the structure of whey proteins (Tolkach and Kulozik, 2007; Nicolai et al., 2011), of starch granules (Ratnayake and Jackson, 2008; Liu et al., 2009; Schirmer et al., 2013) and of carrageenan chains (Piculell, 2006; Nunez-Santiago et al., 2011). The interactions occurring between these ingredients have been studied and, for a variety of blends, the rheological behavior was analyzed along the batch thermal history (Verbeken et al., 2006; Doublier and Durand, 2008; Noisuwan et al., 2009; Huc et al., 2014; Matignon et al., 2014a, 2014b, 2015). The preparation of dairy desserts at industrial scale includes, among other steps, thermal processing under continuous flow. The phenomena of fluid flow, heat transfer and product transformation are strongly coupled within heat exchangers: transformation affects the characteristics of the product (e.g., particle sizes), with consequences on its rheological behavior and hence on the velocity field inside the processing unit. In turn, fluid flow influences heat transfer while the temperature level drives the transformation rate. As a consequence, the final structure of the liquid product can depend not only on the interactions between the ingredients but also on the geometry and on the thermal and dynamical operating conditions associated with the heat exchanger.

To predict the transformation of a liquid food product along its thermo-dynamical history is a challenging task. Physics-based and observation-based modeling approaches constitute complementary tools for food product, processes, and equipment designers. 
experimentally (Datta, 2008). The phenomena of fluid flow, heat transfer, and product transformation need to be considered in the case of the thermal processing of liquid food products under continuous flow. The rheological behavior of liquid food products is typically non-Newtonian and temperature-dependent; therefore, it is difficult to derive analytical solutions for the conservation equations of mass, momentum and energy.

Computational Fluid Dynamics (CFD) has been employed to study a number of problems in food engineering and related disciplines (Norton and Sun, 2006; Galeazzo et al., 2006; Lemus-Mondaca et al., 2011; Khatir et al., 2013; Norton et al., 2013; Rocha et al., 2013; Defraeye, 2014). However, limited efforts were devoted to coupled problems involving liquid food products whose rheological behavior evolves as the transformation progresses along the processing pathway. Bouvier et al. (2014) studied the thermal denaturationaggregation of whey proteins flowing under turbulent flow in a plate heat exchanger; those authors obtained promising agreement between model predictions and observations of the transformation state reached by the liquid product, after assuming a simple rheological behavior for the whey protein solutions under consideration (Newtonian, temperaturedependent). Liao et al. (2000) considered a more complex rheological behavior and developed a numerical model coupling fluid flow, heat transfer and gelatinization of waxy rice starch paste; the apparent viscosity of the product was described through a power law, and both the consistency coefficient and the behavior index were assumed to be temperature-dependent. We can argue that describing the rheological behavior as a function of the local temperature is not a robust strategy. It can be shown that the characteristics of the liquid product, and hence its rheological behavior at a given position in the heat exchanger, depend not only on the local conditions but also on the thermal (and eventually dynamical) histories associated with the fluid parcels running at this position (Chantoiseau et al., 2012; Plana-Fattori et al., 2013). The two-way coupling between product transformation, fluid flow and heat transfer phenomena 
via the rheological behavior constitutes a robust strategy for predicting the transformation of a liquid product along its thermo-dynamical history.

In the logical continuation of previous efforts (Plana-Fattori et al., 2013), this study presents a numerical model for predicting the transformation of a starch suspension running throughout an existing four-heating-section tubular exchanger. We focus on a given starch suspension (type and concentration), and the parameters relevant to the numerical model are estimated through our own experimental protocol at laboratory scale. Both the swelling kinetics and the rheological behavior are represented more realistically than in that previous study; on the one hand, a threshold temperature is assumed for the swelling kinetics rate (rather than an Arrhenius-like approximation); on the other hand, the progressive shearthinning behavior of the starch suspension is described. Later, we compare model predictions of the swelling state reached by the suspension, with observations obtained at pilot scale by running the tubular heat exchanger whose geometry and operating conditions are considered in the numerical model. The objective of this study was double: firstly to implement the coupled model for thermal processing at pilot scale by applying key model parameters obtained from experimental work at laboratory scale, and secondly to assess the improvement that this coupled model represents relatively to a simpler approach, based on the assumption of plug-flow and radially-independent temperatures. Results constitute a meaningful step towards the implementation of numerical models able to represent the variety of dynamical and thermal conditions experienced by realistic food fluid parcels during their pathway in the processing unit. They will be useful for the design of starch suspension thermo-mechanical treatments.

\section{Coupled physical problem}

We are interested in the phenomena of fluid flow, heat transfer and liquid product 
transformation occurring within a tubular heat exchanger which is running under stationary

109 conditions. Conservation equations for mass, momentum and energy can be expressed as:

$$
\vec{\nabla} \cdot(\rho \vec{u})=0
$$

$$
\rho(\vec{u} \cdot \vec{\nabla}) \vec{u}=\vec{\nabla} \cdot\left(-p \vec{I}+\eta\left(\vec{\nabla} \vec{u}+(\vec{\nabla} \vec{u})^{T}\right)-\frac{2}{3} \eta(\vec{\nabla} \cdot \vec{u}) \vec{I}\right)
$$

$$
\rho C_{P}(\vec{u} \cdot \vec{\nabla}) T=\vec{\nabla} \cdot(\lambda \vec{\nabla} T)
$$

113 where $\vec{u}$ is the velocity (magnitude in $\mathrm{m} / \mathrm{s}$ ), $p$ is the pressure (Pa), $T$ is the temperature (K); $\rho$

114 is the product's density $\left(\mathrm{kg} \cdot \mathrm{m}^{-3}\right), \eta$ its apparent viscosity (Pa.s), $C_{P}$ its specific heat capacity $115\left(\mathrm{~J} \cdot \mathrm{kg}^{-1} \cdot \mathrm{K}^{-1}\right)$, and $\lambda$ its thermal conductivity $\left(\mathrm{W} \cdot \mathrm{m}^{-1} \cdot \mathrm{K}^{-1}\right)$.

116 In this exploratory study focus is on the transformation of an aqueous suspension of 117 chemically-modified waxy maize starch. Under heating, this liquid product undergoes a quite 118 simple transformation: starch granules swell without either rupture of swollen granules or 119 release of soluble species in water (Matignon et al., 2015). Hence, the volume occupied by the 120 granules can indicate the transformation state regarding its influence on the apparent viscosity 121 of the starch suspension. At a given time in the thermal history of a suspension droplet, the 122 solid volume fraction $\Phi$ can be estimated as:

$$
\Phi=\Phi_{0}\left(D / D_{0}\right)^{3}
$$

124 where $D(\mu \mathrm{m})$ is the volume mean diameter of starch granules; values $D_{0}$ and $\Phi_{0}$ correspond to the condition of untreated starch, before any thermal treatment. The transformation state 126 associated with the starch suspension can also be indicated by the dimensionless value of the 127 volume mean diameter (also known as swelling degree, $S$ ):

$$
S=\left(D-D_{0}\right) /\left(D_{M A X}-D_{0}\right)
$$

129 where $D_{M A X}$ is the volume mean diameter after the maximum thermal treatment here 130 considered.. In the case of a modified waxy starch suspension in water, the variation in the 
131 swelling degree over time can be described using a second-order kinetics equation

132 (Lagarrigue et al., 2008):

$$
\frac{d S}{d t}=V\{T\}(1-S)^{2}
$$

134 where $V$ is the temperature-dependent swelling kinetics rate $\left(\mathrm{s}^{-1}\right)$. Equations $(4,5,6)$

135 summarize the product swelling for a travelling droplet in the starch suspension. The 136 following conservation equation puts in evidence the inherent coupling which occurs between 137 starch swelling, fluid flow and heat transfer at every position of the processing unit:

$$
\vec{u} \cdot \vec{\nabla} S=V\{T\}(1-S)^{2}+\vec{\nabla} \cdot\left(d_{S} \vec{\nabla} S\right)
$$

139 where $d_{S}$ is a diffusion coefficient $\left(\mathrm{m}^{2} \cdot \mathrm{s}^{-1}\right)$. Equation (7) states that the swelling state results

140 from a) convective transport, b) temperature-dependent swelling of starch granules, and c)

141 diffusion around the position under consideration. The coefficient $d_{S}$ considered in this 142 equation expresses the Brownian (random) diffusion affecting the starch granules in the 143 suspension as well as some diffusion between parallel pathways along the exchanger.

144 Governing equations $(1,2,3,7)$ are solved in this study with the help of numerical 145 modeling tools throughout a sequence of computational domains, as summarized in Section 4.

146 The first step of our modeling approach is the description of the transformation kinetics and 147 the rheological behavior of the liquid product as functions of the state variables.

\section{Estimation of model parameters}

\subsection{Experimental work}

The liquid product is a $3.42 \% \mathrm{w} / \mathrm{w}$ starch suspension in water. Chemically-stabilized and cross-linked waxy maize starch (acetylated adipate distarch, $C^{*}$ Tex 06205) was kindly supplied by Cargill (Baupte, France). It consisted of at least $99 \%$ of amylopectin and a maximum of $0.4 \% \mathrm{w} / \mathrm{w}$ of endogenous proteins. The product was prepared by adding the 
starch powder to a $0.1 \mathrm{M} \mathrm{NaCl}$ aqueous solution. Before any thermal treatment, the resulting

156 liquid remained at $50{ }^{\circ} \mathrm{C}$ for 30 minutes under continuous gentle stirring. Test tubes of $50 \mathrm{~mL}$

157 were used to ensure an equivalent thermal history for all the fluid parcels contained in the

158 sample, while being large enough to enable further analyses. Stirring was performed with a

159 magnetized bar under permanent rotation $(500 \mathrm{rpm})$ inside the test tube.

160 Thermal treatments consisted of a heating and a cooling step, both under continuous

161 stirring. The role of the cooling step was to stop product transformation as rapidly as possible

162 in order to associate different "heating times" with their corresponding "swelling states". The

163 heating step started when the product sample was removed from the $50{ }^{\circ} \mathrm{C}$ water bath and

164 immersed immediately in the second water bath, which was maintained at $90{ }^{\circ} \mathrm{C}$. The cooling

165 step started when the sample was removed from the hot water bath and immersed

166 immediately in the third water bath, maintained at about $4{ }^{\circ} \mathrm{C}$. The product's temperature was

167 initially between 62 and $92{ }^{\circ} \mathrm{C}$ (depending on heating duration) and then rapidly fell. The

168 cooling step was halted when the temperature reached $10^{\circ} \mathrm{C}$.

169 The product's temperature was recorded every 15 seconds during the whole heating

170 and cooling steps. The choices regarding the temperature in the hot water bath $\left(90^{\circ} \mathrm{C}\right)$ and the

171 heating duration (up to 64 minutes) enabled significant changes in the particle size

172 distribution and apparent viscosity. Temperatures close to $90{ }^{\circ} \mathrm{C}$ are involved in industrial

173 starch processing (see for instance Thomas and Atwell, 1999).

$174 \quad$ Figure 1A summarizes the thermal history obtained after each test: starting at $50+/-$

$1750.2{ }^{\circ} \mathrm{C}$, the product's temperature firstly increased during the prescribed heating time and then

176 decreased during the cooling step. Tests are labeled in terms of heating time duration.

177 The particle size distribution associated with each sample was measured using a

178 Malvern Mastersizer 2000 laser granulometer (Malvern Instruments Ltd, United Kingdom)

179 equipped with a $300 \mathrm{~mm}$ Fourier cell (range: $0.05-879 \mu \mathrm{m}$ ). Drops of product were placed in 
180 the cell $(100 \mathrm{~mL})$ until obscuration reached about $20 \%$, corresponding to a dilution of $1 / 100$.

181 Typical values were assumed for the real and imaginary parts of the refractive index of starch 182 granules (1.53 and 0.01; Nayouf et al., 2003). Samples were analyzed twice within less than

18315 minutes at room temperature, and the volume mean diameter was retained for further 184 application. For a given sample, the two estimates of the volume mean diameter were always 185 closer than $0.5 \mu \mathrm{m}$.

186 Rheological measurements were performed using a MCR 301 rheometer (Anton Paar, 187 Austria) equipped with coaxial cylinders. The temperature was controlled with a Peltier system. The flow behavior of the suspension was measured at $20{ }^{\circ} \mathrm{C}$. Increasing and

189 decreasing shear scans were performed stepwise following a logarithmic scale, firstly from 1 190 to $500 \mathrm{~s}^{-1}$ and then from 500 to $1 \mathrm{~s}^{-1}$. Each shear scan was performed twice, and the whole 191 sequence took less than 15 minutes. The range 1 to $500 \mathrm{~s}^{-1}$ includes the maximum shear rate expected at the heat exchanger.

\subsection{Kinetics parameters}

Figure $1 \mathrm{~B}$ presents the volume mean diameter as a function of the heating time. This

196 display offers evidence that the first four minutes of heating play a major role in driving the swelling state of the starch suspension. Between 1 and 8 min of heating, replicating a test associated with a given heating time can allow volume mean diameters differing by some micrometers. After 64 minutes of heating, the replicates agreed by better than $1{ }^{\circ} \mathrm{C}$ in 200 temperature and better than $0.5 \mu \mathrm{m}$ in volume mean diameter.

The influence of temperature on the swelling kinetics rate is a challenging issue when it comes to representing the transformation of starch suspensions under heating. Indeed, as revealed by studies performed since the 1940 s, starch granules can suddenly increase many 
suspension also increases rapidly (Freund, 1944). Such a sudden influence of temperature on

206 the swelling kinetics rate can be approximated by:

$$
\begin{array}{lll}
V\{T\}=0 & \text { if } \quad & T<T a, \\
V\{T\}=V a(T-T a) & \text { if } & T>T a,
\end{array}
$$

209 where $T a$ is a threshold temperature and $V a$ is a constant value $\left(\mathrm{s}^{-1} \cdot{ }^{\circ} \mathrm{C}^{-1}\right)$. Recent observations 210 have shown that the changes in starch granule size become significant above a certain 211 temperature (e.g. Malumba et al., 2013); from this perspective, equations (8) constitute a first212 order approximation for such a change in the swelling kinetics rate.

The volume mean diameter $D$ after a given time $t$ depends on the whole thermal history of the sample, since the beginning of the thermal treatment (integration of equation 6):

$$
D\{t\}=D_{0}+\left(D_{M A X}-D_{0}\right)(1-1 /(1+X\{t\}))
$$

can be used to estimate the parameters $V a$ and $T a$, after exposing the starch suspension to a number of thermal treatments.

All the available tests are shown in Figure 1. Parameters $V a$ and $T a$ were estimated from tests corresponding to the heating times of $1 \mathrm{~min}$ (three replicates), $1.5 \mathrm{~min}, 2 \mathrm{~min}$ (three replicates), $4 \mathrm{~min}$ (two replicates) and $8 \mathrm{~min}$. Sample temperatures corresponding to these five heating times were about $62,70,72,83$, and $89{ }^{\circ} \mathrm{C}$ respectively. Tests corresponding to the heating times of zero (no hot bath) and 64 minutes allowed assessing the extreme values $D_{0}$

$225=16.3 \mu \mathrm{m}$ and $D_{M A X}=43.3 \mu \mathrm{m}$. The values for parameters $V a$ and $T a$ were estimated by 226 minimizing the sum of squared deviations between the experimental values of $D$ and those 227 calculated from equation (9), considering their respective thermal histories; we obtained $T a=$ $61.1^{\circ} \mathrm{C}$ and $V a=3.7910^{-3} \mathrm{~s}^{-1} \cdot{ }^{\circ} \mathrm{C}^{-1}$. 
Figures $1 \mathrm{~B}$ and $1 \mathrm{C}$ compare volume mean diameter values obtained from experiment 230 and predicted through equation (9), assuming the longest thermal history (heating time 64 $231 \mathrm{~min})$. Predictions agreed with experiment by better than $3 \mu \mathrm{m}$, and often better than $1 \mu \mathrm{m}$. 232 The averaged relative error between predictions and experimental values is about $6 \%$ for 233 heating times from 0 to 64 minutes.

It must be noted that the swelling kinetics described by equations (6) and (8) is empirical; these equations describe how the thermal history of suspension droplets can be translated into changes affecting the volume mean diameter of the starch suspension as seen through laser granulometry. No attempt was made to study the heat and mass transfers occurring between starch granules and the surrounding water. We can anyway estimate the heat penetration time from granule surface down to the center, by considering typical values 240 for the thermal diffusivity of starch (about $210^{-7} \mathrm{~m}^{2} / \mathrm{s}$; see for instance Rodriguez and de la 241 Cruz, 2003). The result obtained (a few milliseconds) is four orders of magnitude smaller than 242 the mean residence time of the starch suspension in the heat exchanger considered (about 50 243 seconds). Therefore, we can assume that starch granules exhibit a uniform temperature, and

244 that it varies during their pathway throughout the heat exchanger in the same manner as the 245 surrounding water temperature.

\subsection{Rheological parameters}

Figure 2 shows the apparent viscosities of pasted starch suspensions gathered through

249 Couette rheometry at $20^{\circ} \mathrm{C}$. These measurements were obtained after the tests corresponding 250 to heating times of zero (no hot bath), 1, 2, 4 and 8 minutes. The starch suspension became 251 shear-thinning as granule swelling progressed, suggesting describing the apparent viscosity 252 through an Ostwald power law with a flow behavior index depending on the swelling state. In 253 addition, the apparent viscosity increased with the heating time, suggesting that the 
consistency coefficient can be expressed as a function of the swelling state too. Finally, as a consequence of the relatively low mass concentration of starch in the suspension $(3.42 \%)$, the apparent viscosity at a given swelling state is expected to decrease with the local temperature, following a behavior similar to that exhibited by pure water.

The apparent viscosity associated with the starch suspension is hereinafter described using the following approximations:

$$
\begin{aligned}
& \eta\{\dot{\gamma}, \Phi, T\}=K\{\Phi, T\} \dot{\gamma}^{n\{\Phi\}-1} \\
& K\{\Phi, T\}=k_{1} \exp \left(k_{2} \Phi\right) \eta_{\text {water }}\{T\} \\
& n\{\Phi\}=n *+(1-n *) \exp \left(-k_{3}\left(\Phi-\Phi_{0}\right)\right)
\end{aligned}
$$

where $K$ is the consistency coefficient $\left(\mathrm{Pa} . \mathrm{s}^{\mathrm{n}}\right), n$ is the flow behavior index, $\dot{\gamma}$ is the shear rate $\left(\mathrm{s}^{-1}\right)$ and $\eta_{\text {water }}$ is the dynamic viscosity associated with pure water (Pa.s). Equation (10c) expresses that the flow behavior index exhibits an asymptotic pattern towards the value $n^{*}$ as the solid volume fraction increases. Equations (10) express the mean dependence of the apparent viscosity with the shear rate, the solid volume fraction, and the temperature, while requiring only few parameters. More-detailed descriptions could reconcile the Newtonian plateau and the shear-thinning behavior (see for instance the grey squares in Figure 2); however, such an improvement would require a higher number of parameters.

The parameters required by equation (10) were estimated from the experimental values shown in Figure 2. Best fit values were estimated by minimizing the sum of squared deviations between the predictions and experimental values of apparent viscosity; we obtained $k_{1}=0.662 \mathrm{~s}^{\mathrm{n}-1}, k_{2}=13.6, k_{3}=4.91$ and $n^{*}=0.55$. Lines in Figure 2 indicate the predictions of the apparent viscosities corresponding to the five thermal treatments; the averaged relative error between predictions and experimental values is about $17 \%$. 
empirical, with no considerations on the changes affecting starch granules under thermal treatment. Equations (10a) to (10c) associate the apparent viscosity of the starch suspension and the volume mean diameter of starch granules provided by Couette rheometry and laser granulometry respectively; changes in size are explicitly described via the volume mean diameter, while changes in other starch granules' characteristics (like shape and deformability) are implicitly accounted for in the mean general behavior described through equations (10) by modifying the values of constants $\mathrm{k} 1, \mathrm{k} 2$ and $\mathrm{k} 3$.

\section{Numerical model}

The heat exchanger under consideration is represented in Figure 3A. It is constituted by four tubular heating sections, one holding section, and a number of short curved tubes which are here grouped into three "bends". The liquid product executes counter-flow with respect to super-heated water along the heating sections; the product travels through the holding section and also the bends under thermally-insulated conditions. Figure $3 \mathrm{~B}$ summarizes how the heat exchanger is represented in the numerical model: a sequence of two-dimensional, axi-symmetrical computational domains. Considering a volume flow rate of $15 \mathrm{~L} / \mathrm{h}$, the mean residence time is about 50 seconds.

Table 1 summarizes the boundary conditions assumed for the radial $u_{r}$ and axial $u_{z}$ components of the velocity, for the temperature $T$, and for the swelling degree $S$. Some of these boundary conditions are closely related to the operating conditions which were specified in running the heat exchanger, namely the volume flow rate $(\dot{V})$, and the temperature at key positions: at the exchanger's inlet $\left(T_{1}\right)$, at the second heating section's outlet $\left(T_{2}\right)$, and at the fourth heating section's outlet $\left(T_{3}\right)$. These three temperatures allowed us to estimate, through global energy budget considerations, the averaged inward heat flux to be applied as boundary condition at the walls of the first and the second heating sections (about $6930 \mathrm{~W} / \mathrm{m}^{2}$ ) and at 
303

the walls of the third and the fourth heating sections (about $4210 \mathrm{~W} / \mathrm{m}^{2}$ ).

Looking for the resolution of equations which govern the coupled phenomena, every computational domain has to be subdivided into a number of small, non-overlapping cells. The rectangular geometry of these domains suggests the adoption of rectangular cells characterized by dimensions $d r$ and $d z$ along the domain's radius and axis respectively. We chose cells whose length is four times their width $(d z / d r=4)$, as a compromise for representing gradients along both directions. Three grids were successively assumed, each of them associated with an increasing number of identical cells in the radial direction: $n r=2^{5}=$ $32,2^{6}=64$, and $2^{7}=128$. For the last grid, we obtain $n z=6400$ in the case of our heating sections (length $800 \mathrm{~mm}$ ); considering all the domains required to represent the heat exchanger, the final number is over 4.3 million cells. The mesh resolution corresponding to $n r$ $=2^{7}$ is the highest allowed by computer memory capabilities (Intel Xeon CPU X5650@2.67 GHz, 64-bits, 32-Gb RAM computer).

Governing equations (1, 2, 3, and 7) are solved under steady-state conditions by applying the finite-element method as implemented in the simulation package COMSOL Multiphysics, version 4.4 (Zimmermann, 2006). The solution of the large linear system resulting from the linearization of the coupled equations is reached with the help of the Multifrontal Massively Parallel Sparse Direct Solver (MUMPS; Amestoy et al., 2001, 2006). Satisfactory model convergence was reached after assuming the diffusion coefficient $d_{S}=$ $10^{-8} \mathrm{~m}^{2} \cdot \mathrm{s}^{-1}$ in equation $(7)$.

Lastly, we are aware that curved tubes situated between two successive heating or holding sections can induce some mixing which tends to homogenize temperature and liquid product properties. Such an influence can be significant, as put in evidence through numerical modeling (Hajmohammadi et al., 2013) as well as analysis of experimental residence time distributions (Ndoye et al., 2012). In developing our numerical model, the curved tubes 
328 ("bends") situated between successive heating or holding sections are assumed to play the role 329 of thermally-insulated perfectly-mixed reactors. On the one hand, the mass-weighted value of 330 the product temperature remains unchanged while the fluid parcels travel from the bend's inlet

331 to its outlet. On the other hand, additional transformation is allowed should the product 332 temperature exceed the threshold value $T a=61.1^{\circ} \mathrm{C}$ (see Section 3).

\section{Results}

Figure 4 presents the main results obtained with the numerical model throughout the heating and the holding sections of the heat exchanger. Grey rectangles indicate the curved tubes (bends) situated between two successive sections. The results were obtained using $n r=$ $2^{7}=128$ rectangular cells in the radial direction when building the mesh in all the computational domains.

The temperature field is exhibited in display A. In the heating sections (domains He1, $\mathrm{He} 2, \mathrm{He} 3$, and $\mathrm{He} 4)$, the starch suspension is warmed from the wall: its temperature increases more rapidly in the vicinity of the wall than at the axis of symmetry.

The starch suspension undergoes progressive transformation should its temperature 344 exceed the threshold value $T a=61.1{ }^{\circ} \mathrm{C}$. The volume mean diameter and the solid volume 345 fraction are exhibited in displays B and C respectively. In the heating sections, their patterns 346 match the temperature field. In the bends, the product is mixed and subject to additional 347 transformation. Indeed, the fluid leaving the bends is characterized by mass-weighted values 348 of solid volume fraction of $3.58,5.36$, and $8.21 \%$, which are gradually higher than the values 349 at the outlets of the preceding heating sections: $3.57,4.82$, and $7.63 \%$, respectively. No 350 transformation occurs in the holding section because it succeeds a bend whose outlet temperature $\left(60.1^{\circ} \mathrm{C}\right)$ is lower than the threshold value $T a$. 
exchanger's inlet, the apparent viscosity is associated with low values (about $0.7 \mathrm{mPa} . \mathrm{s}$ ) and

354 Newtonian behavior due to the occurrence of untreated starch granules only ( $\Phi=\Phi_{0}$ in 355 equation 10c). Moving forward in the heat exchanger, the apparent viscosity is slightly 356 affected before the onset of starch swelling $(T=T a)$. Beyond this point, the transformation 357 state progresses; as a result, the liquid becomes shear-thinning (the flow behavior index 358 decreases with $\Phi$ in equation 10c) while the apparent viscosity values rise (the consistency 359 coefficient increases with $\Phi$ in equation $10 \mathrm{~b}$ ). The swelling state is the highest at the wall of 360 the fourth heating section's outlet (domain He4).

361 The apparent viscosity of the starch suspension is here assumed to decrease with 362 temperature following the behavior associated with pure water (equation 10a). The apparent viscosity decreases at the axis of symmetry throughout the two first heating sections (He1 and 364 He2) because the temperature rises under low transformation. Inversely, the temperature's 365 influence on the apparent viscosity can be dominated by that associated with the swelling 366 state when the latter is significant, like in the vicinity of the wall near the outlet of the fourth 367 heating section.

The progressive transformation of the starch suspension affects its rheological 369 behavior, which in turn drives the flow field in the heat exchanger. The velocity magnitude 370 and the shear rate predicted by the numerical model are presented in displays D and E. At the 371 heat exchanger's inlet, a fully-developed velocity profile is assumed. In the first heating 372 section (domain $\mathrm{He} 1$ ), the velocity magnitude decreases at the axis from the inlet to the outlet, 373 whereas it increases in the vicinity of the wall; such a result can be related to the apparent 374 viscosity values at the wall, which decrease as a consequence of progressive warming under 375 low product transformation. In the three other heating sections ( $\mathrm{He} 2, \mathrm{He} 3$ and $\mathrm{He} 4)$, on the 376 contrary, the velocity magnitude increases at the axis and decreases near the wall as a consequence of product transformation and increase in apparent viscosity near the wall: fluid 
parcels travelling in the vicinity of the wall are slowed down, while those running at the axis undergo acceleration. Such a feature is quite severe in the fourth heating section; relatively high shear rate values are obtained towards its outlet, along a tongue-like region which separates the vicinity of the heating wall (where velocity is vanishing) and the region near the axis (where velocity is the highest).

Figure 5 displays the radial distribution of the volume mean diameter at the outlet of the last heating section (domain He4) as predicted by numerical model simulation after assuming three mesh resolutions. Figure 5A shows results obtained with the highest mesh resolution here considered $(n r=128)$, while Figure 5B presents the differences between results from a given mesh and those corresponding to $n r=128$. Firstly, these differences are often negative (swelling is underestimated); secondly, they become stronger as the mesh 389 becomes coarser; finally, their strongest values occur at about $2.5 \mathrm{~mm}$ from the axis, where 390 the radial variation of the volume mean diameter is the highest. These findings can be explained by the progressively-finer representations of the gradients of state variables as the 392 mesh resolution increases.

The influence of mesh resolution can also be assessed in terms of volume mean 394 diameter which corresponds to the mass-weighted value of the solid volume fraction at the 395 outlet of a given section of the heat exchanger. After assuming 32, then 64, and finally 128 396 cells in the radial direction, the bulk values of the volume mean diameter predicted by the 397 numerical model were respectively of $18.19,18.26$ and $18.30 \mu \mathrm{m}$ at the outlet of the second 398 heating section, and $25.37,25.42$ and $25.44 \mu \mathrm{m}$ at the outlet of the fourth heating section. 399 Differences between results corresponding to two successive meshes decrease as the latter 400 become finer, suggesting a convergence-like behavior. We argue that a further leap in mesh 401 resolution, from $n r=2^{7}=128$ to $n r=2^{8}=256$, would allow closer results, with differences 402 between respective predictions of the volume mean diameter smaller than $0.05 \mu \mathrm{m}$. 
Figures 4 and 5 put in evidence that we have satisfactorily solved the coupled 404 problem: while Figure 5 shows that we reached some degree of convergence in solving the equations which govern the relevant phenomena, the two-dimensional fields displayed in Figure 4 are physically consistent. Assessing the performance of model predictions requires comparisons with experimental values. Such a comparison can be performed in terms of mass-weighted values of the swelling state resulting from numerical model simulations. the operating conditions which were applied in numerical modeling simulations (see Table 1).

411 The starch suspension was sampled three times at the outlet of both the second and the fourth 412 heating sections, and immediately cooled down to about $4{ }^{\circ} \mathrm{C}$ to avoid additional product 413 transformation. The size distribution analysis of the product samples provided volume mean 414 diameter values of about 16.5 and $31.6 \mu \mathrm{m}$ respectively after the second and the fourth 415 heating sections, with standard deviations of $0.4 \mu \mathrm{m}$. Considering the numerical model 416 simulations which were conducted with the highest mesh resolution allowed, the bulk values 417 for the predicted volume mean diameter after those two heating sections were respectively $418 \quad 18.30$ and $25.44 \mu \mathrm{m}(+11 \%$ and $-19 \%$ respectively compared to the experimental values).

419 The level of agreement of numerical coupled modeling with experiment can be 420 compared with that obtained through a simpler modeling approach. The simplest way to 421 characterize the path followed by fluid parcels along a heat exchanger consists in neglecting 422 the radial dependence of both velocity and temperature. In such a one-dimensional model, it is 423 assumed that fluid parcels move according to a plug-flow velocity field, and that they are 424 exposed to a temperature which depends only on the distance from the exchanger inlet. The 425 swelling state of the starch suspension at selected positions of the heat exchanger was 426 estimated through equations (9). For this, the swelling kinetics rate was represented as in the 427 numerical coupled model; in building the thermal history, the bulk temperature was assumed 
to vary linearly along the heating sections, and to be constant along the bends and the holding section. At the outlet of the second heating section, the predicted volume mean diameter is identical to the value assumed as boundary condition at the exchanger's inlet; this result is easily understandable because the temperature value at the second heating section's outlet $\left(60.1^{\circ} \mathrm{C}\right)$ is lower than the threshold value $T a=61.1^{\circ} \mathrm{C}$. Starch swelling takes place along the

433 following sections according to this one-dimensional model; at the outlet of the fourth heating 434 section, the predicted volume mean diameter is $21.5 \mu \mathrm{m}$ ( $-32 \%$ compared to the 435 experimental value).

436 We can summarize that: a) when the suspension bulk temperature does not reach the 437 threshold value $T a$, the plug-flow and radially-independent temperature approach is unable to 438 predict any starch swelling, contrarily to the numerical coupled model; b) when that threshold 439 is overcome, the simpler approach underestimates the swelling state reached by the starch 440 suspension. Starch swelling can be compared in terms of volume mean diameter value 441 increase between the exchanger's inlet and outlet: we obtain $(31.6-16.3)=15.3 \mu \mathrm{m}$ from 442 experiment at pilot scale, $(25.4-16.3)=9.1 \mu \mathrm{m}$ from the numerical coupled model, and $443(21.5-16.3)=5.2 \mu \mathrm{m}$ from the simpler approach. In other words, the numerical model 444 predicts the bulk swelling state of the starch suspension at a level of agreement $(-41 \%$ in 445 volume mean diameter increase) which is better than that reached after assuming plug-flow 446 and radially-independent temperature $(-66 \%)$.

447 Finally, a number of reasons can contribute to explain the differences between 448 predictions from the numerical coupled model and respective experimental values. Firstly, the 449 curved tubes (bends) were assumed, in numerical model simulations, to play the role of 450 thermally-insulated perfectly-mixed reactors; actually, we expect the occurrence of slight 451 cooling and incomplete mixing, whose consequences on product transformation are difficult 452 to anticipate. Secondly, starch swelling under heat treatment was assumed to follow a single 
453 temperature-dependent swelling kinetics (equation 6), independently on the granule size. The

454 influence of starch granule size on the swelling onset has been scarcely studied (Myllarinen et 455 al., 1998; see references in Sasaki and Matsuta, 1998); however, no generalization seems 456 possible regarding the starch type. On the other hand, we cannot discard some experimental 457 bias in sampling the starch suspension while it flows in the heat exchanger.

\section{Conclusions and Forthcoming Work}

\section{Conclusions}

The key parameters describing the swelling kinetics and the rheological behavior of a starch suspension were estimated from a limited number of experiments at laboratory scale, after studying small volumes of product under heat treatment and continuous agitation. The application of these parameters allowed model predictions of the final swelling state reached by the starch suspension which did agree, to some extent, with observations conducted while running the heat exchanger. We can therefore conclude that kinetics and rheological model parameters can be transferred from laboratory to pilot scale.

The plug-flow hypothesis implies no influence of product viscosity on the velocity 470 field, and therefore no coupling between fluid flow, heat transfer and transformation. Such a 471 simpler approach provides worse estimates of the final swelling condition reached by starch 472 granules in suspension, relatively to those obtained with the numerical coupled model. We 473 conclude that the consideration of two-way coupling between the relevant phenomena 474 constitutes a positive improvement in looking for realistic predictions of the product's transformation level. 
This study indicates three key issues that deserve attention in implementing numerical coupled models to represent the transformation of realistic food fluid parcels during their pathway in thermal processing units.

Firstly, after representing the heat exchanger under consideration by a sequence of axisymmetrical two-dimensional (2D) domains, the most obvious following step should be to solve the coupled problem by considering the actual three-dimensional (3D) geometrical characteristics of the equipment. In fact, the thermal mixing due to the secondary flow in curved tubes can be more or less effective depending on the flow rate and the fluid rheological behavior (e.g. Cvetkovski et al., 2015). Inclusion of secondary flow is certainly a positive improvement, and its implementation requires higher computer memory and time resources. The challenging task to solve a similar coupled problem by considering the tubular heat exchanger schematized in Figure $3 \mathrm{~A}$ is already under way. the following step towards more realistic predictions from the numerical model, even in the case of a relatively simple liquid product like a starch suspension. Towards such a goal, experiments were conducted with an optical microscope coupled to a warming plate in order 494 to continuously observe the starch granules' behavior during thermal treatments. Indeed, visual observation of individual granules suggested us that, in the case of modified waxy maize starch, the swelling mechanism presents some stochastic nature while being associated 497 with diffusion of surrounding water into the granule.

Finally, the whole strategy could be adapted to product formulations associated with 499 increasing complexity and industrial relevancy, for instance by studying starch swelling in 500 skim milk and later by adding carrageenan. The notion of swelling degree (associated with 501 starch granules in water) could be replaced by that of "filling degree" associated with all objects floating in the continuous phase. Further attention should be paid to estimating the 
503

relevant solid volume fraction. The main structure of the numerical model could be maintained, as the changes would only affect the key parameters describing transformation kinetics and rheological behavior.

\section{Acknowledgements:}

The research leading to these results received funding from the Carnot Institute Qualiment (INRA, France). We acknowledge Stephan Savarese, Benjamin Loubet and Thierry Gengler (COMSOL France) and Vincent Nicolas (IRSTEA) for fruitful discussions regarding the COMSOL Multiphysics 4.4 software package, as well as Qing Li, Ihssane El Mokhtari, Hela Ferchichi and Emilie Auger (trainees at UMR 1145 GENIAL) for their dedication in helping us conduct experimental and numerical work.

\section{References}

Amestoy, P. R., Duff, I. S., L'Excellent, J.-Y., Koster, J. (2001). A fully asynchronous multifrontal solver using distributed dynamic scheduling. SIAM Journal of Matrix Analysis and Applications, 23, 15-41.

Amestoy, P. R., Guermouche, A., L'Excellent, J.-Y., Pralet, S. (2006). Hybrid scheduling for the parallel solution of linear systems. Parallel Computing, 32, 136-156.

Bouvier, L., Moreau, A., Ronse, G., Six, T., Petit, J., Delaplace, G. (2014). A CFD model as a tool to simulate beta-lactoglobulin heat-induced denaturation and aggregation in a plate heat exchanger. Journal of Food Engineering, 136, 56-63. 
528 Chantoiseau, E., Plana-Fattori, A., Doursat, C., Flick, D. (2012). Coupling fluid flow, heat transfer and thermal denaturation-aggregation of beta-lactoglobulin using an Eulerian / Lagrangian approach. Journal of Food Engineering, 113, 234-244.

532 Cvetkovski, C. G., Reitsma, S., Bolisetti, T., Ting, D. S. K. (2015). Heat transfer in a U-bend 533 pipe: Dean number versus Reynols number. Sustainable Energy Technologies and 534 Assessments (in press).

Datta, A. K. (2008). Status of physics-based models in the design of food products, processes, and equipment. Comprehensive Reviews in Food Science and Food Safety, 7, 121-129.

Defraeye, T. (2014). Advanced computational modelling for drying processes - a review. Applied Energy, 131, 323-344.

Doublier, J. L., Durand, S. (2008). A rheological characterization of semi-solid dairy systems.

\section{3} Food Chemistry, 108, 1169-1175.

French, D. (1944). Physical properties of starch. In R. W. Kerr (Ed.), Chemistry and Industry of Starch (pp. 113-129). Academic Press, New York.

548 Galeazzo, F. C. C., Miura, R. Y., Gut, J. A. W., Tadini, C. C. (2006). Experimental and

549 numerical heat transfer in plate heat exchanger. Chemical Engineering Science, 61, 7133$550 \quad 7138$. 
552 Hajmohammadi, M. R., Eskandari, H., Saffar-Avval, M., Campo, A. (2013). A new

553 configuration of bend tubes for compound optimization of heat and fluid flow. Energy, 62, $554 \quad 418-424$

556 Huc, D., Matignon, A., Barey, P., Desprairies, M., Mauduit, S., Sieffermann, J. M., Michon, 557 C. (2014). Interactions between modified starch and carrageenan during pasting. Food 558 Hydrocolloids, 36, 355-361.

560 Khatir, Z., Paton, J., Thompson, H., Kapur, N., Toropov, V. (2013). Optimisation of the 561 energy efficiency of bread-baking ovens using a combined experimental and computational 562 approach. Applied Energy, 112, 918-927.

564 Lagarrigue, S., Alvarez, G., Cuvelier, G., Flick, D. (2008). Swelling kinetics of waxy maize and maize starches at high temperatures and heating rates. Carbohydrate Polymers, 73, 148566155.

Lemus-Mondaca, R. A., Vega-Galvez, A., Moraga, N. O. (2011). Computational simulation and developments applied to food thermal processing. Food Engineering Reviews, 3, 121135.

572 Liao, H.-J., Rao, M. A., Datta, A. K. (2000). Role of thermo-rheological behaviour in 573 simulation of continuous sterilization of a starch dispersion. Transactions of the Institution of 574 Chemical Engineers, 78C, 48-56.

576 Liu, H., Xie, F., Yu, L., Chen, L., Li, L. (2009). Thermal processing of starch-based 


\section{9}

polymers. Progress in Polymer Science, 34, 1348-1368.

Malumba, P., Jacquet, N., Delimme, G., Lefebvre, F., Bera, F. (2013). The swelling behaviour of wheat starch granules during isothermal and non-isothermal treatments. Journal of Food Engineering, 114, 199-206.

Matignon, A., Barey, P., Desprairies, M., Mauduit, S., Siefferman, J. M., Michon, C. (2014a). Starch / carrageenan mixed systems: Penetration in, adsorption on or exclusion of carrageenan chains by granules ?. Food Hydrocolloids, 35, 597-605.

Matignon, A., Moulin, G., Barey, P., Desprairies, M., Mauduit, S., Sieffermann, J. M., Michon, C. (2014b). Starch / carrageenan / milk proteins interactions studied using multiple staining and Confocal Laser Scanning Microscopy. Carbohydrate Polymers, 99, 345-355.

Matignon, A., Neveu, A., Ducept, F., Chantoiseau, E., Barey, P., Mauduit, S., Michon, C. (2015). Influence of thermo-mechanical treatment and skim milk components on the swelling behavior and rheological properties of starch suspensions. Journal of Food Engineering, 150, 1-8.

Myllarinen, P., Autio, K., Schulman, A. H., Poutanen, K. (1998). Heat-induced structural changes of small and large barley starch granules. Journal of the Institute of Brewing, 104, 343-349.

00 Nayouf, M., Loisel, C., Doublier, J. L. (2003). Effect of thermomechanical treatment on the rheological properties of crosslinked waxy corn starch. Journal of Food Engineering, 59, 
603

604 Ndoye, F. T., Erabit, N., Alvarez, G., Flick, D. (2012). Influence of whey protein aggregation 605 on the residence time distribution in a tubular heat exchanger and a helical holding tube 606 during heat treatment process. Journal of Food Engineering, 112, 158-167.

607

608 Nicolai, T., Britten, M., Schmitt, C. (2011). Beta-lactoglobulin and WPI aggregates: 609 Formation, structure and applications. Food Hydrocolloids, 25, 1945-1962.

610

611 Noisuwan, A., Hemar, Y., Wilkinson, B., Bronlund, J. E. (2009). Dynamic rheological and 612 microstructural properties of normal and waxy rice starch gels containing milk protein 613 ingredients. Starch/Starke, 61, 214-227.

614

615 Norton, T., Sun, D.-W. (2006). Computational fluid dynamics (CFD): An effective and 616 efficient design and analysis tool for the food industry: A review. Trends in Food Science and 617 Technology, 17, 600-620.

618

619 Norton, T., Tiwari, B., Sun, D.-W. (2013). Computational Fluid Dynamics in the design and 620 analysis of thermal processes: A review of recent advances. Critical Reviews in Food Science 621 and Nutrition, 53, 251-275.

622

623 Nunez-Santiago, M. C., Tecante, A., Garnier, C., Doublier, J. L. (2011). Rheology and 624 microstructure of kappa-carrageenan under different conformations induced by several 625 concentration of potassium ion. Food Hydrocolloids, 25, 32-41. 
627 Piculell, L. (2006). Gelling carrageenans. In Stephen, A. M. (Ed.), Food Polysaccharides and 628 their Applications (pp. 239-287). Taylor \& Francis, New York.

629

630 Plana-Fattori, A., Chantoiseau, E., Doursat, C., Flick, D. (2013). An Eulerian-Lagrangian 631 approach for coupling fluid flow, heat transfer, and liquid food product transformation. 632 Computers and Chemical Engineering, 52, 286-298.

633

634 Ratnayake, W. S., Jackson, D. S. (2008). Starch gelatinization. Advances in Food Science and 635 Nutrition Research, 55, 221-268.

636

637 Rocha, K. S. O., Martins, J. H., Martins, M. A., Saraz, J. A. O., Lacerda Filho, A. F. (2013).

638 Three-dimensional modeling and simulation of heat and mass transfer processes in porous 639 media: An application for maize stored in a flat bin. Drying Technology, 31, 1099-1106.

640

641 Rodriguez, P., Gonzalez de la Cruz, G. (2003). Photoacoustic measurements of thermal 642 diffusivity of amylose, amylopectin and starch. Journal of Food Engineering, 58, 205-209.

643

644 Sasaki, T., Matsuki, J. (1998). Effect of wheat starch structure on swelling power. Cereal 645 Chemistry, 75, 525-529.

646

647 Schirmer, M., Hochstotter, A., Jeckle, M., Arendt, E., Becker, T. (2013). Physicochemical 648 and morphological characterization of different starches with variable amylose / amylopectin 649 ratio. Food Hydrocolloids, 32, 52-63.

650

651 Thomas, D. J., Atwell, W. A. (1999). "Starches". American Association of Cereal Chemists, 
652 St. Paul (Minnesota, USA).

653

654 Tolkach, A., Kulozik, U. (2007). Reaction kinetic pathway of reversible and irreversible 655 thermal denaturation of beta-lactoglobulin. Lait, 87, 301-315.

656

657 Verbeken, D., Bael, K., Thas, O., Dewettinck, K. (2006). Interactions between kappa658 carrageenan, milk proteins and modified starch in sterilized dairy desserts. International 659 Dairy Journal, 16, 482-488.

660

661 Zimmerman, W. B. J. (2006). Multiphysics Modelling with Finite Element Methods. World 662 Scientific, Singapore. 
Table 1: Boundary conditions taken into account for the radial $u_{r}$ and axial $u_{z}$ components of the velocity, for the temperature $T$, and for the swelling degree $S$.

\begin{tabular}{|l|l|l|l|}
\hline & fluid flow & heat transfer & transformation \\
\hline inlet $(\mathrm{a})(\mathrm{b})(\mathrm{c})$ & velocity: $u_{r}=0, u_{z}\{r\}$ & temperature: $T\{r\}$ & swelling degree: $S\{r\}$ \\
\hline outlet & null pressure, & convective flux: $\frac{\partial T}{\partial z}=0$ & convective flux: $\frac{\partial S}{\partial z}=0$ \\
\hline axis & symmetry: $u_{r}=0, \frac{\partial u_{z}}{\partial r}=0$ & symmetry: $\frac{\partial T}{\partial r}=0$ & symmetry: $\frac{\partial S}{\partial r}=0$ \\
\hline wall & no slipping: $u_{r}=u_{z}=0$ & flux density $(\mathrm{d})(\mathrm{e})$ & no diffusion: $\frac{\partial S}{\partial r}=0$ \\
\hline
\end{tabular}

(a) first heating section: the suspension is assumed to be at the temperature $T_{1}=43.9{ }^{\circ} \mathrm{C}$, containing untreated starch granules only $(S=0)$; the axial velocity follows the fullydeveloped parabolic profile associated with the volume flow rate $\dot{V}=15 \mathrm{~L} / \mathrm{h}$ (mean velocity $\bar{u}_{z}=0.083 \mathrm{~m} \cdot \mathrm{s}^{-1}$, Reynolds number of about 1040).

(b) other sections, when the preceding one is not a bend: the temperature, the swelling degree and the axial velocity follow the distributions $T\{r\}, S\{r\}$ and $u_{z}\{r\}$, which were predicted at the outlet of the preceding section.

(c) other sections, when the preceding one is a bend: the temperature assumes its massweighted (bulk) value $\widetilde{T}$ at the bend's outlet; the swelling degree assumes the value $\widetilde{S}$ which corresponds to the mass-weighted value $\widetilde{\Phi}$ of the solid volume fraction at the bend's outlet; the axial velocity follows $u_{z}\{r\}=\bar{u}_{z}\left(\frac{3 \widetilde{n}+1}{\widetilde{n}+1}\right)\left(1-\frac{r}{R}\right)^{\frac{\tilde{n}+1)}{\widetilde{n}}}$ where $\widetilde{n}$ is the flow behavior index given through equation (10c) by replacing $\Phi=\widetilde{\Phi}$. 
(d) heating and holding sections: inward heat flux estimated from the section's global energy budget, by taking into account the temperatures $T_{1}=43.9{ }^{\circ} \mathrm{C}$ at the exchanger's inlet, $T_{2}=$ $60.1{ }^{\circ} \mathrm{C}$ at the second heating section's outlet, and $T_{3}=70.0{ }^{\circ} \mathrm{C}$ at the fourth heating section's inlet.

(e) bends: thermal insulation. 


\section{Figure Captions}

Figure 1: Key results regarding the evolution of the starch suspension under thermal treatments: A) the sample thermal history; B) the mean volume diameter as function of the heating time, obtained from experiment and estimated through the second-order kinetics; C) predicted versus experimental values for the mean volume diameter.

Figure 2: Apparent viscosity values at $20^{\circ} \mathrm{C}$ of the starch suspension, after selected thermal treatments. Lines indicate the corresponding predictions of apparent viscosity as a function of shear rate and solid volume fraction.

Figure 3: Three-dimensional (A) and two-dimensional axi-symmetrical (B) schematic representations of the heat exchanger under consideration. The heating sections are indicated in red, the curved tubes (bends) in blue, and the holding section in green. In scheme B, the dashed line and the red continuous lines indicate the axis of symmetry and the heating walls, respectively.

Figure 4: Numerical model predictions for the temperature, the mean volume diameter and the volume fraction associated with starch granules, the velocity magnitude, the shear rate, and the apparent viscosity throughout the heating and holding sections of the heat exchanger.

Figure 5: Mean volume diameter as predicted by the numerical model at the outlet of the fourth heating section: A) results obtained by assuming a mesh consisting of 128 rectangles in the radial direction; B) difference between results obtained by assuming successively 64 , and 32 rectangles in the radial direction, and results shown in the display A. 
temperature during heat treatments

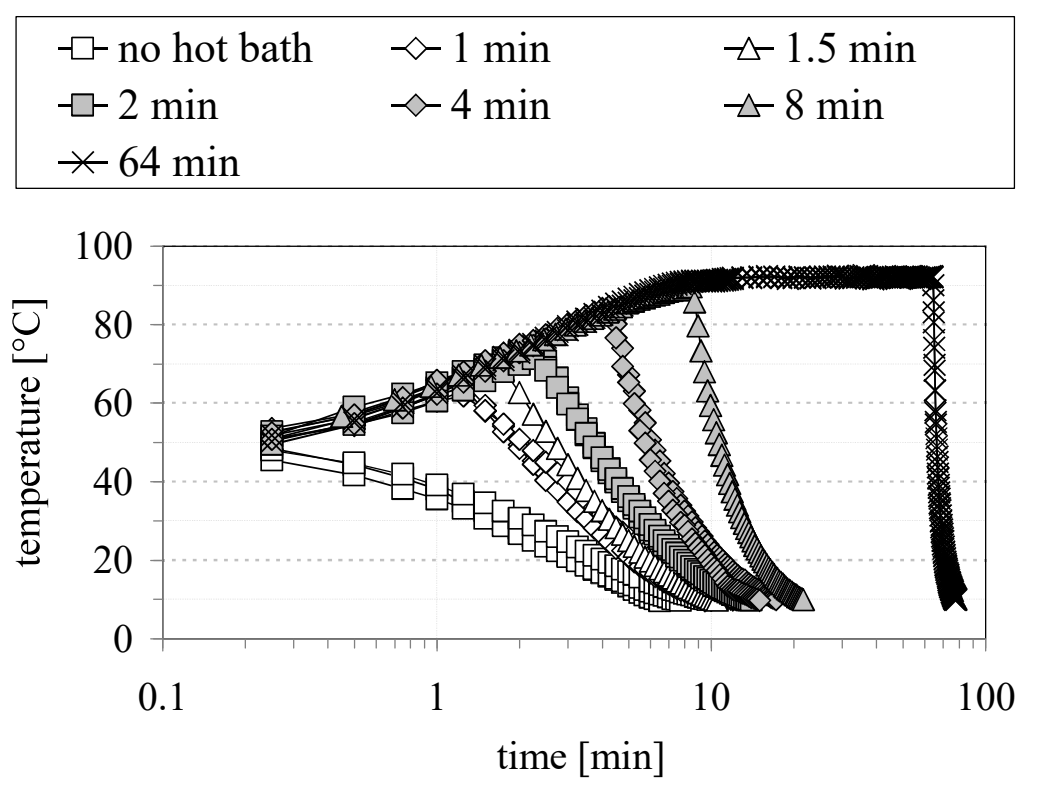

B

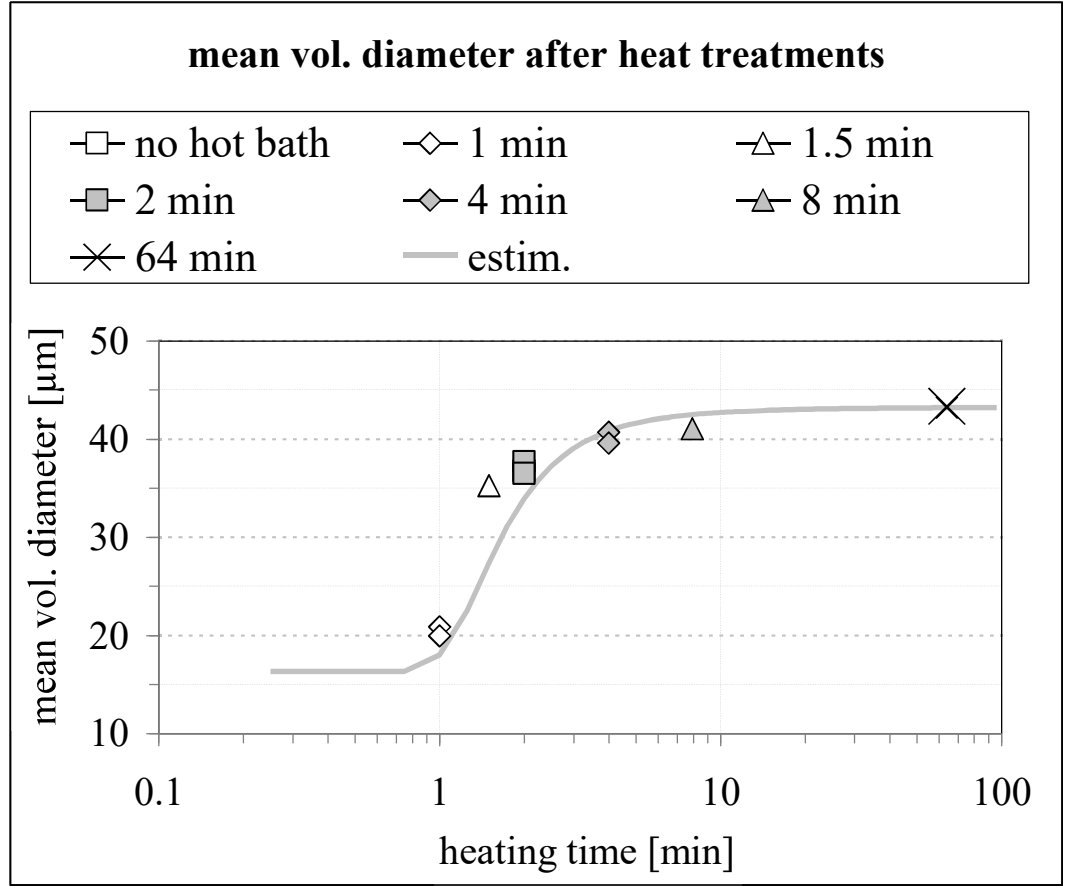

estimates vs. observ. of mean vol. diameter

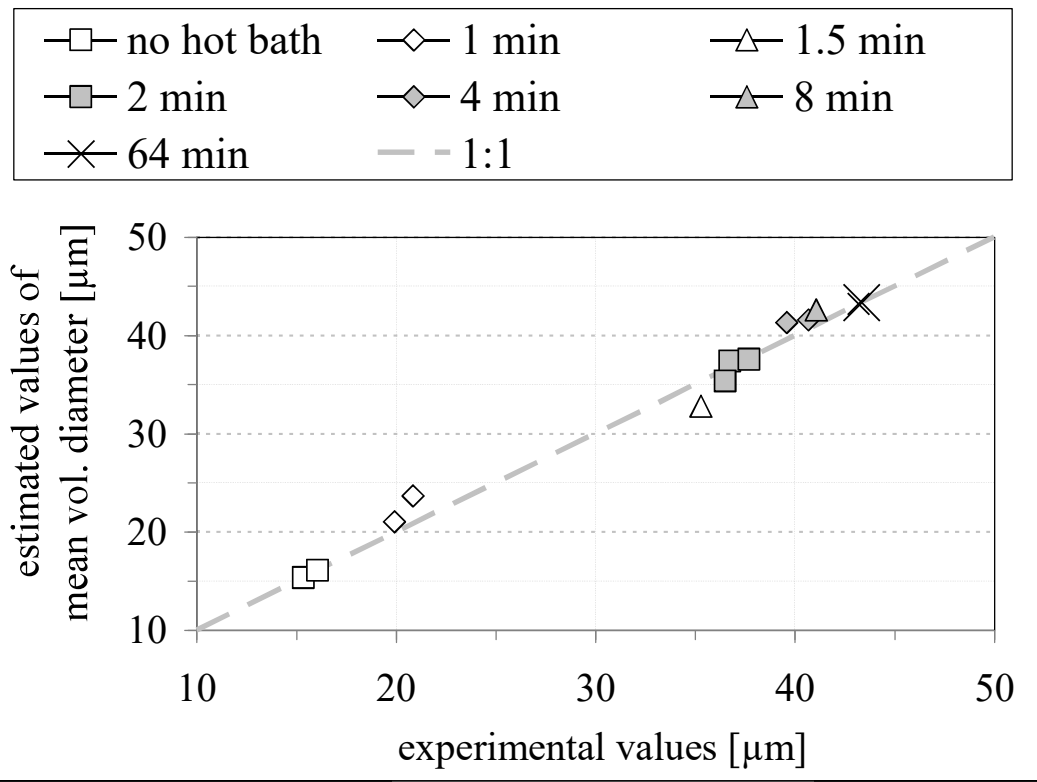




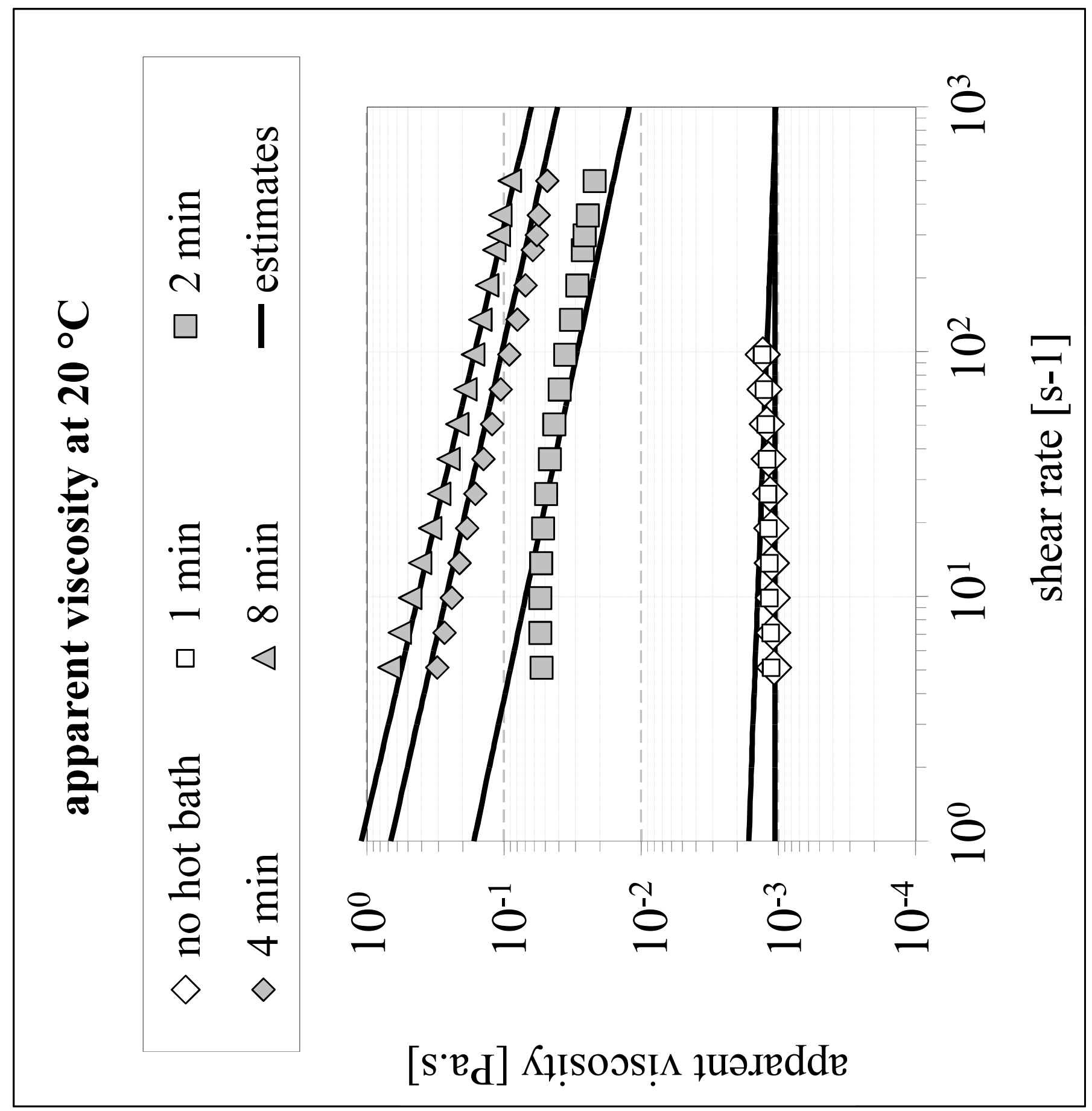




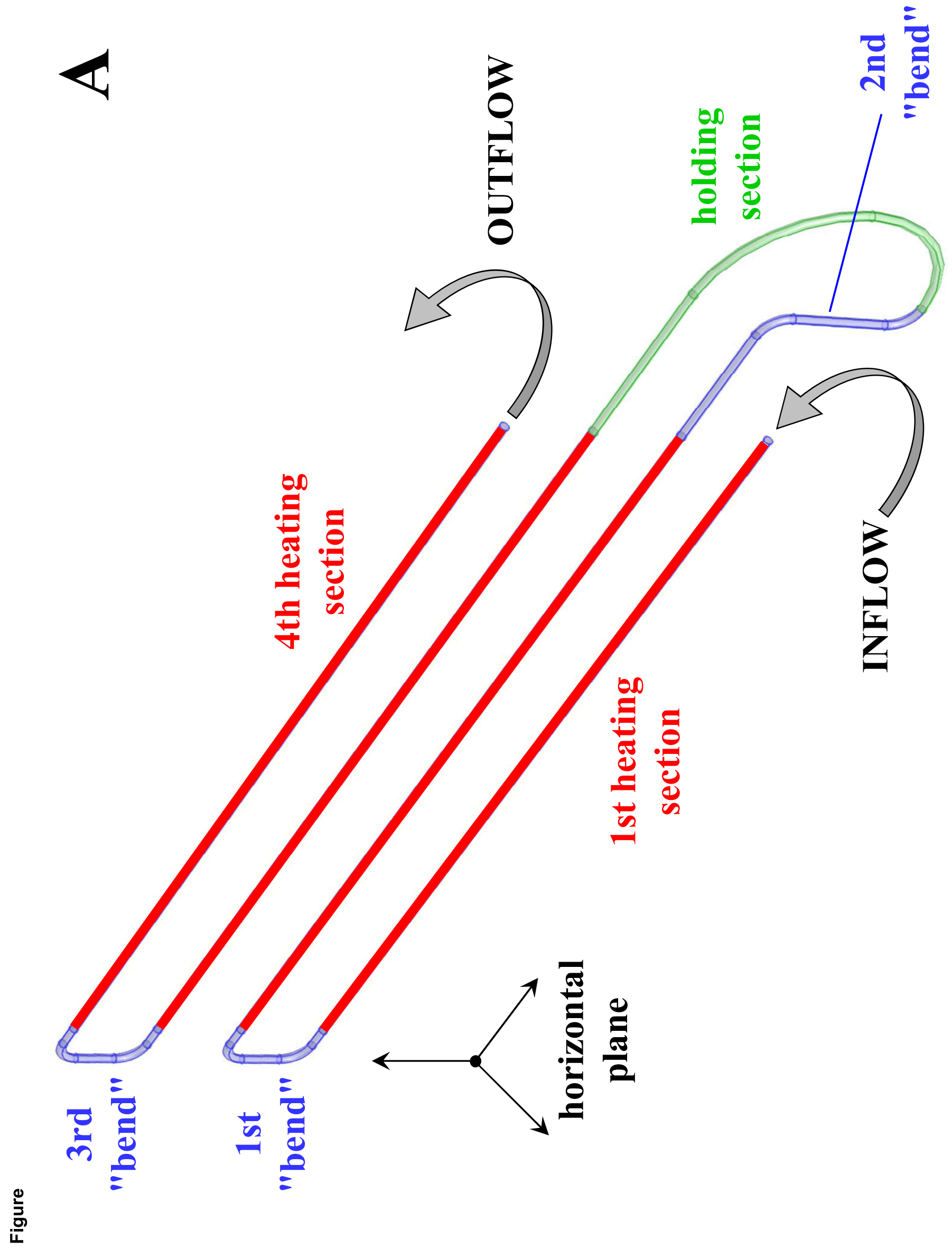


10

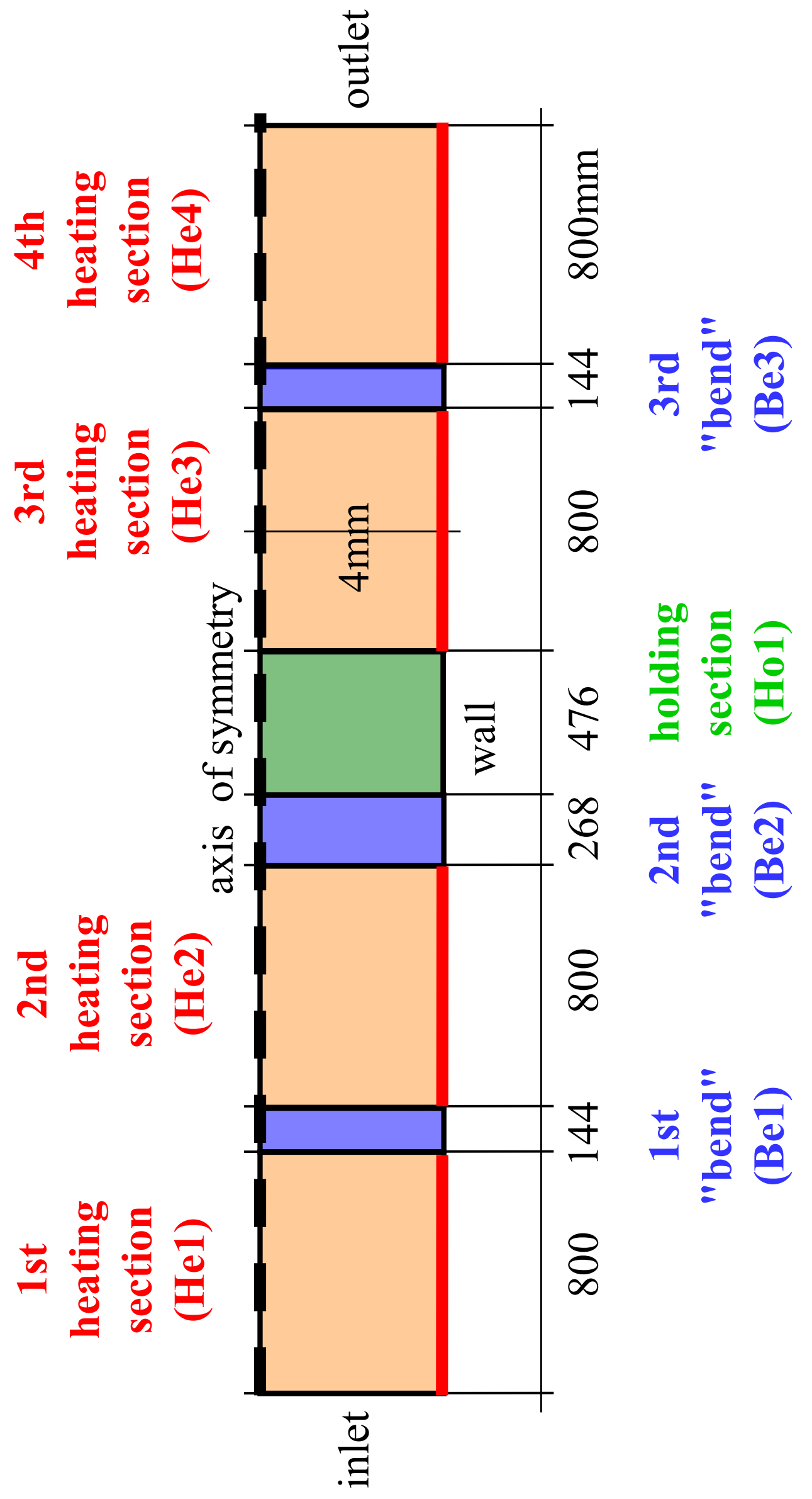



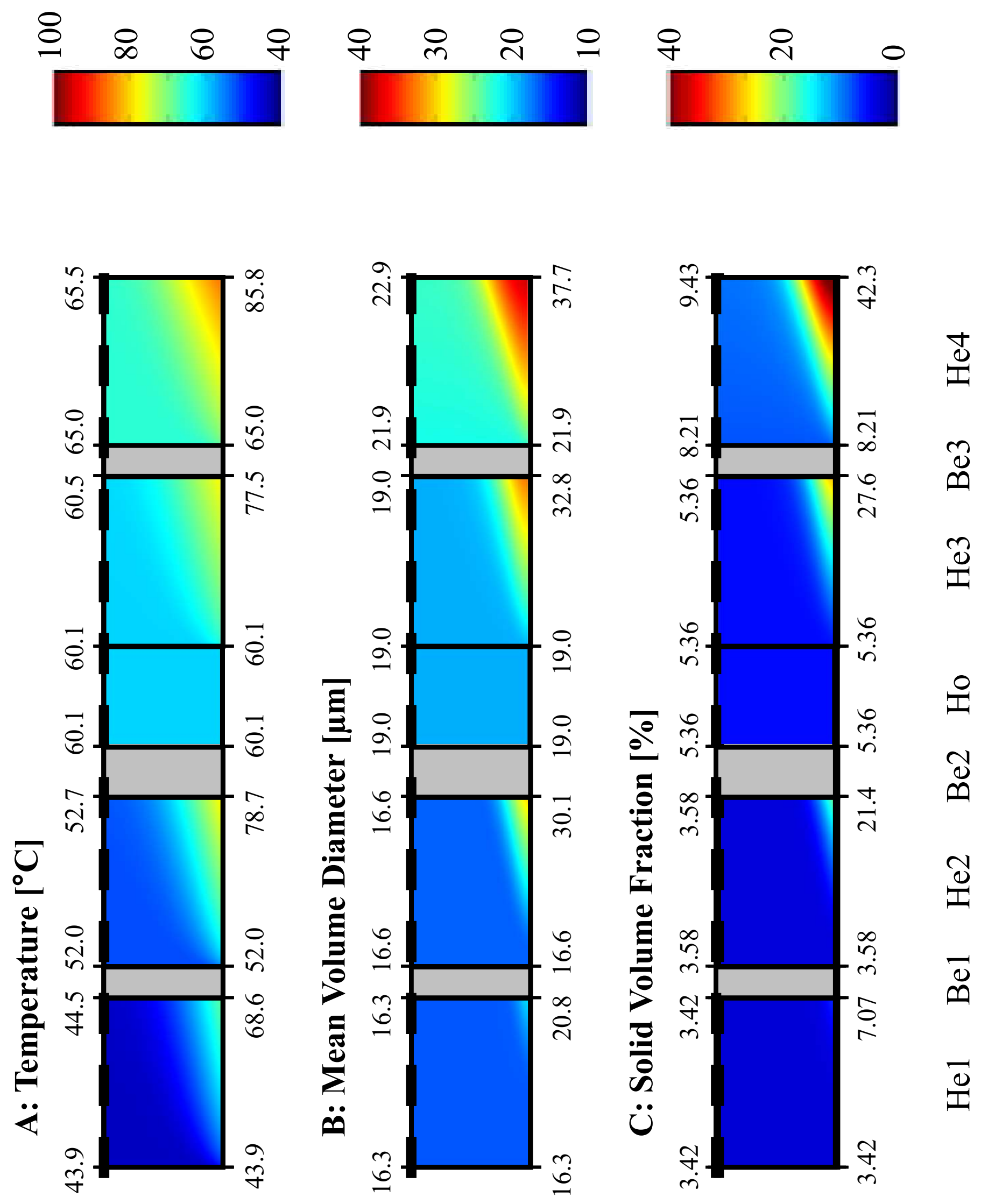

온 

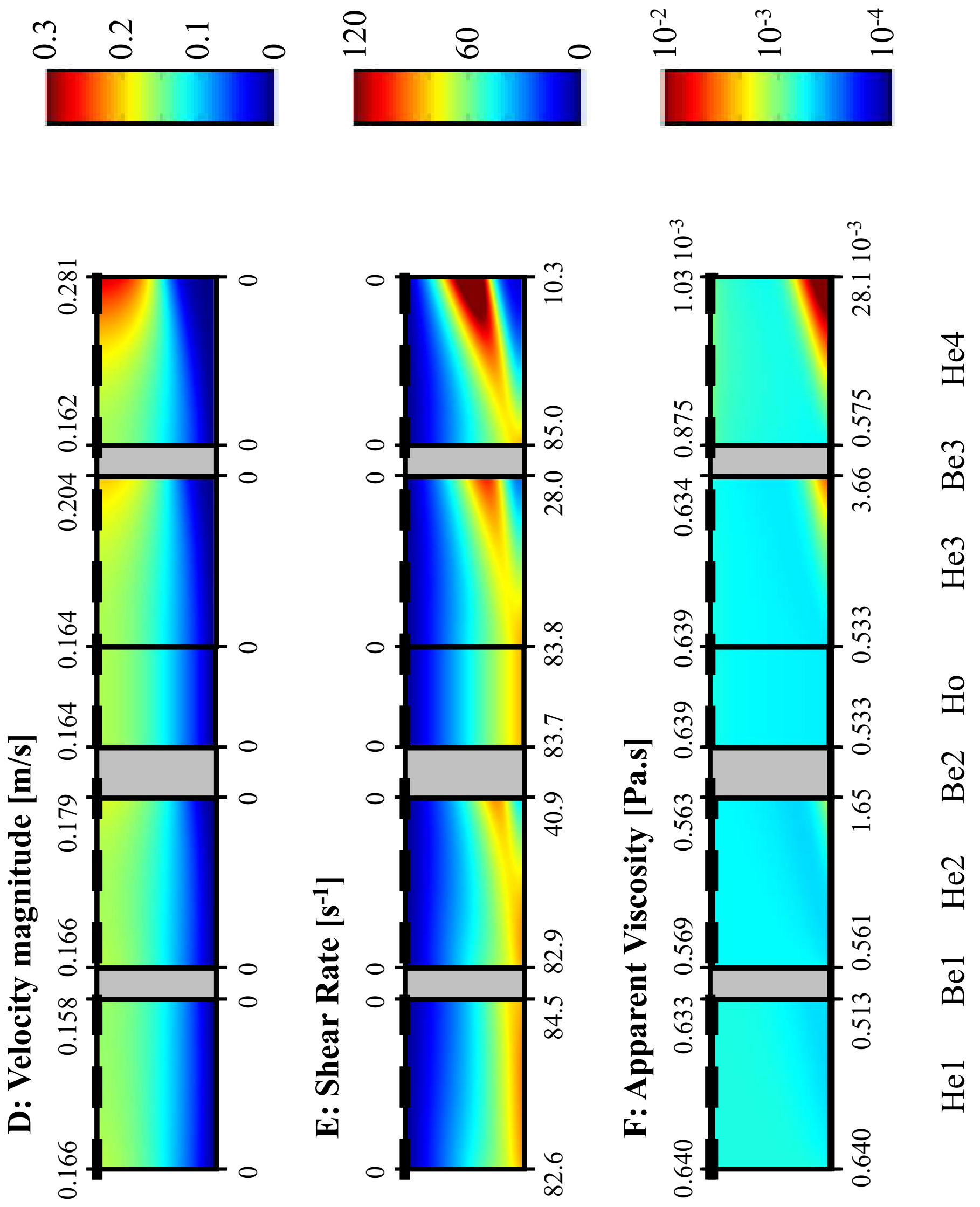

온 

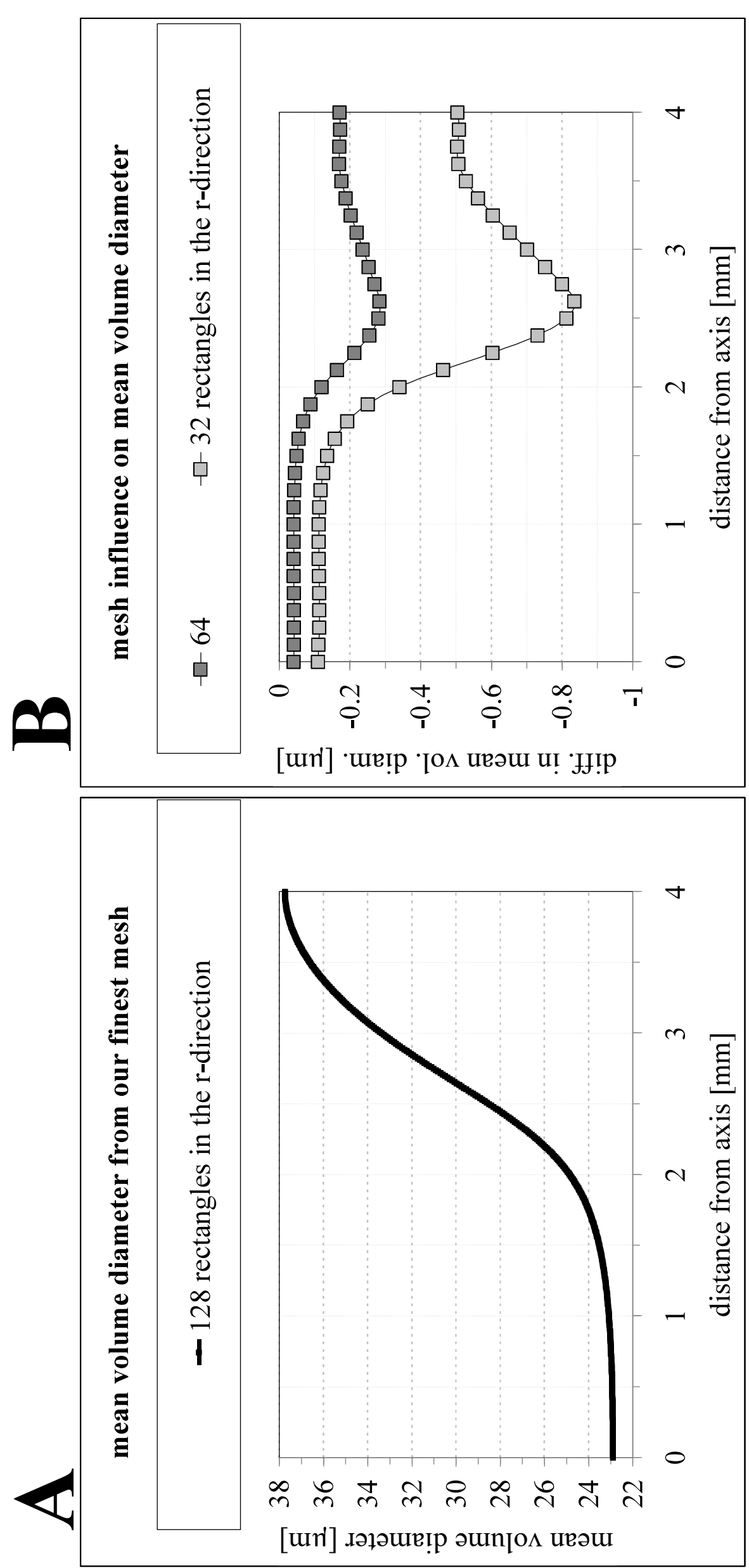
Table 1: Boundary conditions taken into account for the radial $u_{r}$ and axial $u_{z}$ components of the velocity, for the temperature $T$, and for the swelling degree $S$.

\begin{tabular}{|l|l|l|l|}
\hline & fluid flow & heat transfer & transformation \\
\hline inlet $(\mathrm{a})(\mathrm{b})(\mathrm{c})$ & velocity: $u_{r}=0, u_{z}\{r\}$ & temperature: $T\{r\}$ & swelling degree: $S\{r\}$ \\
\hline outlet & null pressure, & convective flux: $\frac{\partial T}{\partial z}=0$ & convective flux: $\frac{\partial S}{\partial z}=0$ \\
\hline axis & symmetry: $u_{r}=0, \frac{\partial u_{z}}{\partial r}=0$ & symmetry: $\frac{\partial T}{\partial r}=0$ & symmetry: $\frac{\partial S}{\partial r}=0$ \\
\hline wall & no slipping: $u_{r}=u_{z}=0$ & flux density $(\mathrm{d})(\mathrm{e})$ & no diffusion: $\frac{\partial S}{\partial r}=0$ \\
\hline
\end{tabular}

(a) first heating section: the suspension is assumed to be at the temperature $T_{1}=43.9{ }^{\circ} \mathrm{C}$, containing untreated starch granules only $(S=0)$; the axial velocity follows the fullydeveloped parabolic profile associated with the volume flow rate $\dot{V}=15 \mathrm{~L} / \mathrm{h}$ (mean velocity $\bar{u}_{z}=0.083 \mathrm{~m} \cdot \mathrm{s}^{-1}$, Reynolds number of about 1040).

(b) other sections, when the preceding one is not a bend: the temperature, the swelling degree and the axial velocity follow the distributions $T\{r\}, S\{r\}$ and $u_{z}\{r\}$, which were predicted at the outlet of the preceding section.

(c) other sections, when the preceding one is a bend: the temperature assumes its massweighted (bulk) value $\widetilde{T}$ at the bend's outlet; the swelling degree assumes the value $\widetilde{S}$ which corresponds to the mass-weighted value $\widetilde{\Phi}$ of the solid volume fraction at the bend's outlet; the axial velocity follows $u_{z}\{r\}=\bar{u}_{z}\left(\frac{3 \widetilde{n}+1}{\widetilde{n}+1}\right)\left(1-\frac{r}{R}\right)^{\frac{(\widetilde{n}+1)}{\tilde{n}}}$ where $\tilde{n}$ is the flow behavior index given through equation (10c) by replacing $\Phi=\widetilde{\Phi}$. 
(d) heating and holding sections: inward heat flux estimated from the section's global energy budget, by taking into account the temperatures $T_{1}=43.9{ }^{\circ} \mathrm{C}$ at the exchanger's inlet, $T_{2}=$ $60.1{ }^{\circ} \mathrm{C}$ at the second heating section's outlet, and $T_{3}=70.0{ }^{\circ} \mathrm{C}$ at the fourth heating section's inlet.

(e) bends: thermal insulation. 